\title{
Um estudo de caso sobre os efeitos da tecnologia no ensino básico de Sabará-MG por meio de projeto de inclusão digital de mulheres
}

\section{A case study on the effects of technology in the basic education of Sabará-MG through a digital inclusion project for women}

Recebido: 29/10/2020 | Revisado: 12/11/2020 | Aceito: 29/11/2020 | Publicado $19 / 04 / 2021$

\section{Luis Fernando Orlande de Almeida} ORCID: https://orcid.org/0000-0003-15249653

Instituto Federal de Minas Gerais

E-mail: luisorlande@gmail.com

\section{Carlos Alexandre Silva}

ORCID: https://orcid.org/0000-0002-55974254

Instituto Federal de Minas Gerais

E-mail: carlos.silva@ifmg.edu.br

Bruno Nonato Gomes

ORCID: https://orcid.org/0000-0001-81349105

Instituto Federal de Minas Gerais

E-mail: bruno.nonato@ifmg.edu.br

\section{Débora Silva Veloso Rocha}

ORCID: https://orcid.org/0000-0002-87991534

Instituto Federal de Minas Gerais

E-mail: debora.veloso@ifmg.edu.br

Éder Aguiar Mendes Oliveira ORCID: https://orcid.org/0000-0003-1493$849 \mathrm{X}$

Instituto Federal de Minas Gerais

E-mail: eder.oliveira@ifmg.edu.br

Cássia do Carmo Pires Fernandes ORCID: https://orcid.org/0000-0002-09701423

Instituto Federal de Minas Gerais

E-mail: cassia.pires@ifmg.edu.br

Como citar:

ALMEIDA, L. F. O.; SILVA, C. A.; GOMES, B. N.; ROCHA, D. S. V. R.; OLIVEIRA, E. A. M. O.; FERNANDES, C. C. P. F. Um estudo de caso sobre os efeitos da tecnologia no ensino básico de Sabará-MG por meio de projeto de inclusão digital de mulheres.

Revista Brasileira da Educação

Profissional e Tecnológica, [S.I.], v. 1, n. 20, p. e11457, abr. 2021. ISSN 2447-1801

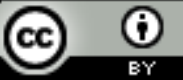

This work is licensed under a Creative Commons Attribution 4.0 Unported License.

\section{Resumo}

Neste artigo apresentamos um estudo de caso sobre os efeitos da tecnologia no ensino básico público da cidade mineira de Sabará, utilizando como amostra alunas de dez escolas públicas da cidade, que integraram um projeto de inclusão digital feminina de fomento federal. Foram avaliadas 65 alunas de diversas escolas públicas da cidade e para se fazer a análise proposta, foram coletadas informações por meio de dois formulários e um teste estratificado com categorias de conhecimento aplicado às alunas e aos instrutores, e em seguida foram realizadas inferências a partir destes dados. Os resultados mostraram uma equiparação por nível de ensino, porém com destaque para o ensino fundamental, além dos resultados sugerirem influência do local de realização do curso durante 0 desenvolvimento do projeto no desempenho do teste de conhecimento.

Palavras-Chave: Tecnologia; Ensino Básico; Inclusão Digital; Pensamento Computacional.

\begin{abstract}
In this article we present a case study on the effects of technology on public basic education in the city of Sabará, using students from ten public schools in the city, who were part of a federally funded female digital inclusion project. 65 students from different public schools in the city were evaluated and in order to carry out the proposed analysis, information was collected using two forms and a stratified test with categories of knowledge applied to the students and instructors, and then inferences were made from these. Dice. The results showed an equivalence by level of education, but with emphasis on elementary education, in addition to the results suggesting the influence of the place of the course during the development of the project on the performance of the knowledge test.
\end{abstract}

Keywords: Technology; Basic Education; Digital Inclusion; Computational Thinking. 


\section{INTRODUÇÃO}

As ferramentas tecnológicas estão cada vez mais presentes no cotidiano da vida moderna, seja para auxiliar na realização de tarefas diárias no ambiente de trabalho ou como forma de lazer. A revolução tecnológica a qual vivemos tem influenciado fortemente a educação, e consequentemente o mercado de trabalho. $O$ Linkedln, maior rede social de negócios do mundo, divulgou em 2019 seu relatório (BERGER, 2019) anual de empregos emergentes, no qual consta as profissões que mais crescem e com boas perspectivas para os próximos anos. Foi constatado que 0 número de profissões relacionadas a inteligência artificial e ciência de dados são as que mais se expandirão pelos diversos setores do mercado. A necessidade do embasamento tecnológico para desempenhar atividades profissionais do futuro, exige que a formação escolar estimule o aprendizado e forneça conhecimento básico e sólido sobre ciências exatas e tecnologias.

A curricularização de disciplinas tecnológicas no ensino básico envolvendo o ensino de programação e robótica, já é realidade em alguns países. A educação STEM (Science-Technology-Engineering-Mathematics) propõe um currículo baseado na ideia de educar os alunos em quatro disciplinas específicas - ciência, tecnologia, engenharia e matemática - em uma abordagem interdisciplinar e aplicada. Os EUA têm feito grandes investimentos nesta área, sobretudo a partir do governo do presidente Barack Obama, o qual investiu em 2011, US $\$ 3,7$ bi em programas federais de educação STEM, além de US\$ 4,3 bi em competições envolvendo esta temática (BREINER et al., 2012).

No Brasil, a inclusão digital e a disseminação do pensamento computacional têm ocorrido gradativamente, porém ainda existe uma grande lacuna no processo de educação nacional quanto a estes quesitos. $O$ uso de tecnologia na educação não representa um componente curricular obrigatório e, apesar de ser elencada entre as dez competências gerais, sua menção se torna genérica como apresentado na Base Nacional Comum Curricular (BNCC):

Compreender e utilizar tecnologias digitais de informação e comunicação de forma crítica, significativa, reflexiva e ética nas diversas práticas sociais (incluindo as escolares), para se comunicar por meio de diferentes linguagens e mídias, produzir conhecimentos, resolver problemas e desenvolver projetos autorais e coletivos. (BRASIL, 2018).

Em regiões de vulnerabilidade social, a inclusão digital se torna mais complexa, tendo em vista a necessidade de se ter mais recursos disponíveis e mãode-obra especializada.

A partir desse contexto, a proposta do presente estudo se aplica na cidade mineira de Sabará. O município é um dos mais antigos do estado de Minas Gerais, Brasil, tendo origem no fim do século XVII e tornado cidade em 1838. Atualmente 
possui uma população estimada superior a 130 mil habitantes de acordo com os dados do IBGE ${ }^{1}$ de 2019. A distribuição de renda na cidade é bastante desigual, sendo que até 2017 o município figurava-se no G100, ou seja, no grupo das 100 cidades brasileiras com mais de 80 mil habitantes com as mais baixas receitas per capita e altos índices de vulnerabilidade, conforme consta no relatório da Frente Nacional de Prefeitos $^{2}$ de 2018. Com o objetivo de contribuir para uma mudança na realidade de Sabará, especificamente na área educacional, a qual é um dos quesitos de avaliação do G100, o Instituto Federal de Minas Gerais campus Sabará (IFMG-Sabará) executa desde 2016 o projeto de extensão Programa Sabará. Esse projeto atua em escolas públicas da cidade, levando o ensino do pensamento lógico e computacional a crianças e adolescentes, na sua maioria em situação de vulnerabilidade social.

A intenção do projeto é oportunizar o ensino de programação e robótica às crianças e adolescentes, por dois motivos principais: a possibilidade futura de estabilidade e mobilidade social, uma vez que o mundo do trabalho atual tem crescente demanda por profissionais especializados na área, e o desenvolvimento de uma consciência, ainda que embrionária, do funcionamento e potencialidade dos diferentes sistemas computacionais contemporâneos, de sites governamentais a aplicativos de grandes corporações, que usam a computação para automatizar a coleta de dados individuais e inferir conhecimentos embasadores de processos de tomada de decisão.

Neste estudo investiga-se o impacto e o efeito da tecnologia no ensino básico de Sabará, tendo como público amostral alunas do projeto de inclusão digital feminina, - PS4W (Programa Sabará for Women), fomentado pelo Conselho Nacional de Desenvolvimento Científico e Tecnológico (CNPq), que é um desdobramento do projeto de extensão Programa Sabará do IFMG-Sabará. O artigo está organizado da seguinte forma: na seção 1 é feita a introdução do trabalho destacando o foco desta pesquisa e a motivação de sua realização, além das ferramentas utilizadas para o seu desenvolvimento. A seção 2 contextualiza a tecnologia no cenário educacional mundial e nacional. Todos os dados deste trabalho foram gerados a partir de um projeto de inclusão digital feminina, o qual é detalhado na seção 3 . Na seção 4 é descrita a metodologia e os instrumentos avaliativos empregados nesta pesquisa. A visualização gráfica, a análise de resultados utilizando técnicas estatísticas em conjunto com os softwares Weka ${ }^{3}$ e Power $B{ }^{4}$ são apresentados na seção 5. Por fim, as considerações finais são expressas na seção 6 .

\section{CONTEXTUALIZAÇÃO DA INFORMÁTICA NA EDUCAÇÃO}

Os computadores, bem como a tecnologia em geral, vêm se integrando cada vez mais ao nosso cotidiano. A partir dos anos 1980, com a larga escala de produção dos computadores pessoais, conhecidos como PCs, o seu uso foi se popularizando, culminando na era da Informação, no final do século XX. A computação está relacionada com a tentativa de solucionar problemas mediante um conjunto de

\footnotetext{
${ }^{1}$ Disponível em: https://www.ibge.gov.br/estatisticas/sociais/populacao/9103-estimativas-depopulacao.html?=\&t=resultados. Acesso em: $11 \mathrm{fev} .2020$.

${ }^{2}$ Disponível em: http://multimidia.fnp.org.br/biblioteca/publicacoes/item/730-g100-edicao-2018. Acesso em: $11 \mathrm{fev} .2020$.

${ }^{3}$ Disponível em: <https://www.cs.waikato.ac.nz/ml/weka/>. Acesso em 13 jan. 2020.

${ }^{4}$ Disponível em: <https://powerbi.microsoft.com/pt-br>. Acesso em 13 jan. 2020.
} 
instruções bem definidas. Estas instruções podem ser entendidas como algoritmos. Estes conceitos tem se disseminado na educação básica, sobretudo por meio do pensamento computacional, o qual surgiu na literatura pelo trabalho de Jeannette Wing, sendo este definido como, "O pensamento computacional envolve a resolução de problemas, o desenvolvimento de sistemas e a compreensão do comportamento, baseando-se nos conceitos fundamentais da ciência da computação". (WING, 2006, p. 33, tradução nossa). ${ }^{5}$

O pensamento computacional envolve habilidades e características fundamentais para a compreensão e resolução de situações complexas cada vez mais presentes em diversas áreas de atuação na atualidade. Podemos citar a "abstração", que permite a construção de modelos para a abordagem de complexos problemas, e a "automação" que pode mecanizar as abstrações. O pensamento computacional tem sido tema de recentes pesquisas, em especial aplicadas ao ensino fundamental e médio. O artigo de Nguyen et al (2019) apresenta o CodeNC, cuja proposta é integrar o pensamento computacional às atividades de ensino da educação básica usando vídeos animados. Esses autores relatam a preocupação com a ampliação da representação de minorias na área de computação, ressaltando a relevância que o governo americano tem dado a esta causa, corroborando com os argumentos de Wing (2006) a respeito do pensamento computacional. De forma resumida, o trabalho descreve um processo de design iterativo, proporcionando a descoberta de formas de integrar conceitos de tecnologia em seis disciplinas que não são da área de computação presentes no currículo do ensino básico.

De acordo com Garcia-Peñalvo (2019), a Sociedade Científica de Informática da Espanha e a Conferência de Diretores e Decanos de Engenharia Informática, publicaram um relatório ${ }^{6}$ no ano de 2018 ressaltando a necessidade social de se incluir a disciplina de informática em todos os níveis de estudos pré-universitários seguindo uma tendência mundial (GROVER; PEA, 2013), tendo como exemplos o modelo do Reino Unido (BERRY, 2013) e o modelo de Israel (GAL-EZER, 1995). Ainda de acordo com Garcia-Peñalvo (2019), a habilidade digital é uma competência essencial proposta pela União Europeia, sendo o conhecimento básico de informática uma necessidade na sociedade atual, assim como os conhecimentos de leitura, escrita ou execução de operações aritméticas.

Um estudo mais amplo a respeito da aplicação da informática no ensino básico é apresentado em Dagiené, Jevsikova e Stupuriené (2019). Neste trabalho, os autores discutiram a estrutura do currículo preliminar de informática no ensino fundamental desenvolvido na Lituânia, porém analisaram a situação do ensino de informática em diferentes localidades, totalizando 52 países ao todo, mais especificamente 34 países da Europa e 18 países não europeus, incluindo países da Ásia, África e América Central. A conclusão é que em 21\% dos países (sendo $91 \%$ destes países da Europa), a informática para o equivalente ao ensino fundamental inicial brasileiro está em desenvolvimento. A diferença entre os níveis educacionais dos países fica mais perceptível quando se conclui que, 33\% dos países pesquisados introduzem informática na $1^{\underline{a}}$ e $2^{\underline{a}}$ série do ensino fundamental; $19 \%$ dos países

\footnotetext{
${ }^{5}$ Computational thinking involves solving problems, designing systems, and understanding human behavior, by drawing on the concepts fundamental to computer science.

${ }^{6}$ Disponível em: http://www.scie.es/wp-content/uploads/2018/07/informe-scie-coddi-2018.pdf. Acesso em: 19 jan. 2020.
} 
começam a ensinar informática a partir da $5^{\mathrm{a}}$ ou $6^{\mathrm{a}}$ série, enquanto no restante dos países analisados a presença da informática se aproxima do ensino médio ou inexiste.

O trabalho de Lockwood e Mooney (2017) propõe uma sistemática revisão bibliográfica a respeito do pensamento computacional na educação, contemplando mais de 200 artigos de referencial teórico. O artigo descreve o pensamento computacional como uma habilidade essencial que todos devem aprender. Verificouse que apesar dos vários trabalhos realizados em diferentes contextos educacionais, o pensamento computacional ainda se encontra em fase inicial de desenvolvimento quando comparado em escala global. A análise da informática é o cerne do trabalho de Hromkovič (2006), o qual busca descrever as principais contribuições e resultados que a informática tem proporcionado ao mundo, além disso discute-se a importância da ciência da computação no currículo escolar e quais tópicos deveriam ser considerados. Tendo em vista a disseminação da robótica educacional, sobretudo em virtude de sua ampla aplicação a distintos níveis de ensino, desde a fase pré-escolar até às pós-graduações, o trabalho de Lathifah, Budiyanto e Yuana (2019) aborda o conceito de aprendizagem STEM, ressaltando sua tendência mundial na educação, e seu impacto no ensino fundamental. Os autores apresentam uma revisão da literatura, a fim de avaliar desenvolvimentos recentes no campo da robótica educacional, além de constatar a adequação da metodologia de aprendizado via desenvolvimento de projetos associada à robótica.

No contexto do ambiente da educação profissional e tecnológica do Brasil, a Revista Brasileira de Educação Profissional e Tecnológica (RBEPT) traz diversos trabalhos que relatam experiências exitosas a respeito da informática na educação, como em (DE ARAÚJO; DE SOUZA; DE MIRANDA SILVA, 2014), no qual são apresentadas contribuições do uso de recursos tecnológicos na formação de professores para a educação profissional a partir dos resultados de atividades de ensino envolvendo a linguagem de programação Scratch. O estudo de caso abordado em (MELENDEZ; EICHLER, 2019) investigou o perfil dos estudantes de uma instituição de educação profissional enquanto possíveis desenvolvedores de jogos digitais, e mostrou a importância desta ferramenta educacional. Ainda na coletânea da RBEPT, o recente artigo de (VENDRUSCULO; DA SILVA MELLO, 2020) descreve uma abordagem híbrida que utiliza tecnologias e experimentação, como o uso de aplicativos, realizada junto a estudantes do $1^{\circ}$ ano do ensino médio integrado - técnico em informática a respeito dos temas ácidos, bases e $\mathrm{pH}$.

Para contextualizar a informática no cenário educacional brasileiro, apresentamos uma revisão da literatura baseada em artigos desenvolvidos entre 1991 a 2020, correspondendo a quase três décadas de discussão científica sobre a temática. As informações foram divididas em três períodos: 1991-2000, 2001-1910 e 1911-2020.

\subsection{PESQUISAS SOBRE INFORMÁTICA NA EDUCAÇÃO BRASILEIRA NO PERÍODO DE 1991 A 2000}

A informática na educação no Brasil começou nos anos 1970 a partir de experiências de algumas universidades, como UNICAMP, UFRJ e UFRGS. Mesmo tendo um histórico de mais de 50 anos, a informática no sistema educacional brasileiro ainda dista de uma consolidação. Uma visão analítica a respeito da informática na 
educação do país é apresentada no artigo de Valente e Almeida (1997). Os autores criticam a preparação inadequada dos professores em decorrência de mudanças pedagógicas propostas por programas como o "Programa Brasileiro de Informática em Educação" de 1997, que tinha o objetivo de promover o uso de tecnologias como ferramenta pedagógica no ensino público fundamental e médio. O programa ainda está em vigor, com o nome de PROINFO (Programa Nacional de Informática na Educação), sendo que em 2007 ele foi reestruturado e passou a ter o objetivo de promover o uso pedagógico das tecnologias de informação e comunicação nas redes públicas de educação básica. O trabalho de Fernandes e Santos (1999) traz um compilado de atividades regulares de pesquisa e desenvolvimento em informática na educação, desenvolvido por grupos brasileiros desde meados dos anos 1970.

\subsection{PESQUISAS SOBRE INFORMÁTICA NA EDUCAÇÃO BRASILEIRA NO PERÍODO DE 2001 A 2010}

O PROINFO novamente é abordado em Arruda e Raslan (2007), no qual são apresentados dados históricos referentes à informática na educação do Brasil de 1997 a 2006. Além da análise detalhada sobre o programa e seus recursos, os autores fazem a seguinte indagação:

[...] mesmo que a formação de professores para uso das Tl's fosse priorizada, como sinaliza o próprio documento oficial do PROINFO, haveria como realizar um trabalho didático-pedagógico significativo sem equipamentos e sem local apropriado para a sua utilização? (ARRUDA; RASLAN, 2007, p. 14).

Também é apontada a implicação do uso de softwares proprietários, os quais encareceram sua aplicação, tornando o programa dependente da tecnologia estrangeira. A informática na educação e o processo de inclusão de alunos com Necessidades Educacionais Especiais (NEEs) na rede regular de ensino é tema do trabalho de Menezes (2005). A pesquisa buscou identificar como a tecnologia computacional tem sido utilizada pelos professores de alunos com NEEs na rede regular de ensino do município de Santa Maria/RS. A autora afirma que:

[...] mesmo que a aprendizagem de conteúdos não seja diretamente favorecida, acreditamos que o uso do computador de forma democrática, igualitária e não excludente proporciona aos alunos com NEEs em processo de inclusão o desenvolvimento da autonomia, da auto-estima, de aspectos sociais e cognitivos do desenvolvimento, que por sua vez possibilitam que esses alunos sintam-se parte integrante dessa turma, rompendo com processos de isolamento e permitindo que eles possam interagir com seus colegas. (MENEZES, 2005, p. 129).

Em Almeida (2008) é indicada a importância das políticas públicas para a implementação de tecnologias digitais na escola, contribuindo para a correção de assimetrias no sistema educacional, tendo em vista o desempenho dos estudantes. 
Além disso, é feito uma retrospectiva histórica com ênfase na origem da informática na educação; integração de mídias e tecnologias e a busca por equipamentos de baixo custo nas escolas.

\subsection{PESQUISAS SOBRE INFORMÁTICA NA EDUCAÇÃO BRASILEIRA NO PERÍODO DE 2011 A 2020}

A pesquisa de Posada, Buchdid e Baranauskas (2016) utiliza tagclouds (nuvem de palavras) para identificar na literatura os trabalhos relacionados à informática na educação, permitindo construir um roteiro dentro do campo de estudo para pesquisadores e profissionais que queiram aprofundar o conhecimento sobre 0 tema.

Os desafios no ensino do pensamento computacional na educação básica brasileira são discutidos em França e Tedesco (2015). Além disso, foi apresentada uma proposta que contribuiu com a aprendizagem de estudantes do nível médio, fazendo uso do desenvolvimento de jogos digitais. Uma seção deste artigo é destinada a análise do pensamento computacional no contexto escolar brasileiro com a apresentação de diversos projetos realizados em diferentes regiões do país. $O$ projeto apresentado em Carvalho, Chaimowicz e Moro (2013) envolveu 11 escolas da zona norte de Belo Horizonte, totalizando 5.979 alunos. O propósito deste trabalho foi inserir o pensamento computacional no ensino médio de escolas de Minas Gerais. Entre os elementos apontados como desafios para a transformação da educação por meio do uso de tecnologias, o trabalho de França e Tedesco (2015) destaca: o currículo escolar, a formação dos professores, os processos de ensinar e aprender, além da aprendizagem de computação. Um estudo comparativo sobre políticas públicas educacionais de inclusão digital entre Brasil e Uruguai é apresentado em Moreira, Lima e Brito (2020). Com a implementação do plano CEIBAL ${ }^{7}$ (Conectividad Educativa de Informática Básica para el Aprendizaje en Línea), o Uruguai atingiu a meta de $100 \%$ de conectividade à internet na educação pré-primária, primária e secundária no país. Porém, os resultados referentes ao Brasil, apontam pontos críticos de implantação de políticas públicas de inclusão digital, em decorrência à descontinuidade da sistematização de projetos, os quais necessitam de sustentabilidade e prazos longos para a sua consolidação.

\section{PROGRAMA DE INCLUSÃO DIGITAL FEMININA}

Os dados coletados para o desenvolvimento desta pesquisa são provenientes de um projeto de inclusão digital para o público feminino, fomentado pelo CNPq, em uma iniciativa que buscava estimular a participação e a formação de meninas e mulheres para as carreiras de ciências exatas, engenharias e computação. Tratavase do edital CNPq/MCTIC № 31/2018 - Meninas nas Ciências Exatas, Engenharias e Computação, o qual obteve mais de 700 submissões pelo Brasil, tendo 85 aprovações por alguns estados do país, e especificamente 8 projetos aprovados no estado de

\footnotetext{
${ }^{7}$ Plano de inclusão e igualdade de oportunidades com o objetivo de apoiar com tecnologias as políticas educativas do Uruguai. Disponível em: https://www.ceibal.edu.uy/es/institucional. Acesso em: 23 fev. 2020.
} 
Minas Gerais. O Programa Sabará for Women (PS4W) foi um destes projetos aprovados e projeto-base para o desenvolvimento da presente pesquisa.

O PS4W é um desdobramento do programa de extensão, Programa Sabará (PS), do Instituto Federal de Minas Gerais campus Sabará (IFMG-Sabará), que promove inclusão digital às escolas da rede pública do município mineiro de Sabará desde 2016. Até o ano de 2018, o PS atendia estudantes da rede pública de ensino da cidade, tanto in loco, em escolas municipais e estaduais, como nas dependências do IFMG-Sabará. A partir de 2019 teve início às atividades do PS4W, atendendo especificamente 4 escolas estaduais in loco, além de três turmas de diversas escolas públicas do município no IFMG-Sabará. Este projeto, em específico, admitia apenas meninas como estudantes do curso, em virtude da caracterização do edital ao qual este projeto era fomentado. Existiam alunas a partir do 6o ano do ensino fundamental até $03^{\circ}$ ano do ensino médio, com idades variando de 12 a 18 anos. O projeto teve duração de 8 meses, sendo dividido em 4 módulos: Logo, Scratch, Python e Robótica. Cada módulo compreendia 16 horas de aula, sendo diluídas em 2 horas semanais. A grande maioria das discentes vieram da rede estadual de ensino, porém, havia também estudantes da rede municipal. A realização do curso ocorreu nas escolas atendidas, ou nas dependências do IFMG-Sabará, caracterizando dois ambientes. Todas essas informações auxiliaram na análise do efeito da tecnologia no ensino básico da cidade, proposto neste artigo. Para enfatizar a relevância do projeto quanto à inclusão digital e seu impacto na sociedade, destacamos alguns acontecimentos:

- Formatura ${ }^{8,9}$, de 80 alunas do PS4W provenientes da rede pública do município de Sabará, contando com a participação de representante da secretaria estadual de educação, secretaria municipal de educação, gabinete da prefeitura, pró-reitoria de extensão do IFMG, direção-geral do campus Sabará, além dos coordenadores do PS4W e Programa Sabará. O evento marcou a reinauguração do local para formaturas de grande porte na cidade;

- A emissora Rede Minas conquistou em março de 2020 o prêmio ${ }^{10,11}$, nacional CONIF de jornalismo, na categoria televisão com a série "Tecnologia Inclusiva" de Renato Franco, com o PS4W compondo a pauta da primeira reportagem desta série;

- O PS4W foi tema de abertura do Seminário Saberes da Extensão ${ }^{12}$, o principal evento institucional do IFMG (Planeta Inovação).

A fim de gerar um ciclo de conhecimento, estudantes do próprio campus foram capacitados tecnicamente e pedagogicamente pelos orientadores do projeto, dentre os quais eram professores atuantes nos cursos técnicos e superiores das áreas de Informática e Comunicação e Engenharia e Controle de Processos, abordando as temáticas de computação e eletrônica, sintetizadas em ensino de programação e

\footnotetext{
${ }^{8}$ Disponível em: https://www2.ifmg.edu.br/portal/noticias/cine-bandeirante-recebe-formatura-doprojeto-de-extensao-sabara-for-women. Acesso em: 02 mar. 2020.

${ }_{9}^{9}$ Disponível em: https://sousabara.com.br/empregos/meninas-de-escolas-publicas-formam-noprograma-sabara-saiba-mais/. Acesso em: 02 mar. 2020.

${ }^{10}$ Disponível em: http://redeminas.tv/serie-do-jornalismo-da-rede-minas-vence-premio-conif/. Acesso em: 02 mar. 2020.

${ }^{11}$ Disponível em: https://www.ifmg.edu.br/portal/noticias/premio-conif-de-jornalismo-e-entregue-arede-minas-pelo-ifmg. Acesso em: 02 mar. 2020.

12 Disponível em: https://www2.ifmg.edu.br/portal/pesquisa-e-pos-graduacao/planeta-inovacao2019/ecossistema-ciencia-e-tecnologia-seminario-de-saberes-da-extensao. Acesso em: 02 mar. 2020.
} 
ensino de robótica. Além disso, a equipe era composta por uma pedagoga que capacitava os instrutores quanto a aspectos didáticos do processo ensino e aprendizagem.

\section{METODOLOGIA E INSTRUMENTOS AVALIATIVOS}

A proposta deste trabalho é avaliar os efeitos da tecnologia no ensino básico de Sabará-MG, utilizando um estudo de caso proveniente de um projeto extensionista de inclusão digital do público feminino, fomentado pelo governo federal. O projeto extensionista é o PS4W, conforme descrito na seção 3.

O teste-base de conhecimento e os formulários entidade aluno-instrutor, que serão discutidos nas seções seguintes, foram aplicados a 65 alunas de 10 escolas públicas da cidade de Sabará. Estudantes das seguintes escolas fizeram o curso ofertado pelo PS4W nas dependências do IFMG-Sabará: E.E. Coronel Adelino Castelo Branco, E.E. General Carneiro, E.E. Juquinha de Almeida, E.E. Prof. Maria Elizabeth Viana, E.E. Paula Rocha e E.M. Rosalina Alves Nogueira. As quatro escolas restantes, E.E. Christiano Guimarães, E.E. Dona Bilú Figueiredo, E.E. Elísio Carvalho de Brito e E.E. Prof. Zoroastro Vianna Passos, fizeram o curso em suas próprias dependências, com exceção do módulo de robótica. A aplicação do teste e dos formulários ocorreu em meados de agosto de 2019, tendo as alunas concluído aproximadamente $60 \%$ dos conteúdos previstos. A realização dos testes e preenchimento dos formulários ocorreram em pouco mais de uma semana.

A fim de coletar informações a serem submetidas a análise estatística para averiguar os efeitos da tecnologia no estudo de caso referenciado, foram propostos indicadores, nos quais se basearam os formulários e o teste de conhecimento desenvolvidos. Neste escopo de informações estavam presentes indicadores técnicos elaborados em conjunto com os orientadores do projeto; indicadores metodológicos construídos em parceria com a pedagoga do PS4W e indicadores de avaliação do ensino, propostos concomitantemente aos instrutores responsáveis pelas turmas. Após o levantamento dos dados e do tratamento quantitativo dos mesmos, a proposta do trabalho consistia em realizar uma análise qualitativa com o intuito de compreender os resultados encontrados dentro do contexto onde o programa de extensão estava inserido, visando compreender o efeito da tecnologia no ensino aplicado ao caso de estudo.

A base de dados desta pesquisa é composta por respostas provindas de um teste de conhecimento específico e dois formulários envolvendo as respostas das discentes e dos docentes referentes ao desenvolvimento do projeto de inclusão digital feminina, PS4W. O teste de conhecimento compreende quatro dimensões: "Angulações e Polígonos", "Lógica", "Resolução de Problemas" e "Pensamento Computacional". A primeira dimensão ("Angulações e Polígonos" ou "Ângulos") é composta por questões envolvendo conceitos e determinação de ângulos, definição e características de polígonos. A segunda dimensão ("Lógica") aborda questões de raciocínio lógico, que não exigem conhecimentos matemático ou computacional prévios, e podem ser resolvidas a partir da habilidade de visualização, percepção de padrões e capacidade de generalização de sequências, além de organização de dados e estruturação do raciocínio. A terceira dimensão ("Orientação e Resolução de Problemas" ou "Resolução") compreende conceitos como a resolução de problemas 
envolvendo orientação espacial, paradigmas computacionais como "dividir para conquistar" e sequenciamento lógico de tarefas. Por fim, a quarta dimensão ("Pensamento Computacional") faz referência a conceitos básicos de lógica computacional envolvendo variáveis, estruturas de repetição e estruturas condicionais.

\title{
4.1 TESTE-BASE DE CONHECIMENTO E SUAS DIMENSÕES
}

Tomando como base as aulas no curso do PS4W, especialmente as referentes ao primeiro módulo, percebeu-se que muitas estudantes apresentavam dificuldade sobre a temática de geometria que se remetia à ângulos, como por exemplo, representar e identificar computacionalmente figuras geométricas que dependiam do conhecimento teórico sobre angulações. Vale ressaltar que essa dificuldade não era esperada tendo em vista que tal conteúdo é, normalmente, desenvolvido a partir do sétimo ano do ensino fundamental e foi abordado nas atividades do projeto sem um nível de dificuldade elevado.

Nesse sentido, verifica-se uma defasagem no que diz respeito ao ensino de geometria no ensino fundamental. De acordo com Marques e Caldeira (2018), o estudo desse ramo da Matemática é comumente postergado e, com frequência, os conteúdos não chegam a ser abordados nos níveis de ensino aos quais se enquadram. Dessa forma, a escolha de tal tema foi consideravelmente relevante e é corroborada pelo trabalho de Santos e Oliveira (2018), que aborda a prática pedagógica em geometria no ensino básico amparado em documentos oficiais tais como os Parâmetros Curriculares Nacionais ${ }^{13}$, Conteúdo Básico Comum ${ }^{14} \mathrm{e}$ bibliografias científicas (PAVANELLO, 1989; LORENZATO, 1995; GAZIRE, 2000). Nas atividades do primeiro módulo do curso do PS4W são comuns a inserção de elementos geométricos. A importância desse conteúdo é enfatizada em:

\begin{abstract}
Em sentido mais abstrato, a Geometria também se constitui, paradoxalmente, em um saber lógico, intuitivo e sistematizado, colocando-se como necessidade primordial na produção do conhecimento e do raciocínio. Nestes aspectos, a Geometria é indissociável da preparação profissional do aluno e do desenvolvimento das habilidades fundamentais na construção de uma carreira. Apontam-se esses argumentos como alguns dos motivos essenciais que justificam a sua importância como conteúdo na grade curricular da Educação Básica. (SANTOS; OLIVEIRA, 2018, p.02).
\end{abstract}

A segunda dimensão do teste de conhecimento abordou a habilidade da lógica de raciocínio. A lógica informal, ou seja, sem a necessidade do uso da formalidade de argumentos e sentenças, atua na construção de formas de argumentação que possam validar mensagens e discerni-las. $O$ desenvolvimento desta habilidade pode auxiliar, como por exemplo, na análise de publicações diárias em meios de comunicação digital ou impresso, cujos textos possam apresentar falácias, que levam a um raciocínio errado com aparência de ser verdadeiro. $\mathrm{O}$

\footnotetext{
${ }^{13}$ Disponível em: http://portal.mec.gov.br/seb/arquivos/pdf/livro03.pdf. Acesso em: 08 mar. 2020.

${ }^{14}$ Disponível em: http://www2.educacao.mg.gov.br/images/matematica.pdf. Acesso em: 08 mar. 2020.
} 
conceito e utilização da lógica estava presente desde o primeiro módulo do curso PS4W. Desta forma, as habilidades de programação foram sendo desenvolvidas gradativamente pelas estudantes. Um interessante estudo (TRÄFF et al., 2019) investigou a relação do raciocínio lógico entre crianças de 9-10 anos sendo preditivas para habilidades de física na faixa etária de 12-13 anos. O estudo constatou que a capacidade de raciocínio lógico é um componente essencial para que as crianças aprendam sobre fatos abstratos da física, conceitos, teorias e aplicação de métodos científicos complexos.

A capacidade de resolver problemas envolvendo percepção espacial, paradigmas computacionais como "dividir para conquistar" e sequenciamento lógico de tarefas, foi abordada na dimensão "Resolução". Algumas bases bibliográficas de referência foram utilizadas como questões da Olimpíada Brasileira de Robótica ${ }^{15} \mathrm{e}$ Brackmann (2017). As características envolvidas nas questões desta dimensão convergem para habilidades e conhecimento de técnicas de programação, além da percepção espacial e dedução lógica inerente às atividades de robótica.

Em alguns países o ensino de programação é obrigatório na grade curricular do ensino básico. Os EUA têm investido bilhões de dólares no modelo STEM (Science, Technology, Engineering, Mathematics) nos últimos anos. No Brasil, apenas recentemente, tem-se discutido formalmente sobre a curricularização do pensamento computacional. Existem várias ações pelo país com a tentativa de ensinar conceitos de computação para alunos do ensino básico, mas esta temática ainda é incipiente na BNCC (Base Nacional Comum Curricular). O trabalho de Grover e Pea (2013) é uma excelente referência bibliográfica para entender o que é o pensamento computacional e qual seu impacto no ensino básico. As questões compreendidas na dimensão "Pensamento Computacional" no teste aplicado, consideram conceitos e conhecimentos de computação que podem ser utilizados sem o uso do computador (computação desplugada). Dentre os conteúdos destacam-se questões envolvendo repetições, condicionais e análise de melhor solução. O teste elaborado está disponível em Teste-Base de Conhecimento ${ }^{16}$.

\subsection{FORMULÁRIOS ENTIDADES ALUNO-INSTRUTOR}

Dois formulários foram aplicados às discentes e instrutores do PS4W, com o intuito de coletar dados, para gerar informação e conhecimento a respeito da qualidade do curso e da metodologia de ensino proposta. O primeiro formulário trata do questionário aplicado às alunas do PS4W, a fim de que estas avaliassem o curso mediante a resposta de perguntas que levavam em consideração tópicos como: motivação e relevância das aulas de programação e robótica, dificuldade de acompanhamento, disponibilidade de tempo às atividades e qualidade e organização do curso. As informações coletadas pelo formulário entidade-aluno forneceram dados para a construção do modelo matemático de regressão, com o propósito de auxiliar na análise dos efeitos da tecnologia aplicado ao ensino básico no caso de estudo

\footnotetext{
15 Disponível em: http://www.obr.org.br/. Acesso em: 14 mar. 2020.

${ }^{16}$ Disponível em: https://drive.google.com/open?id=10lyw7ovnmyvX2uYRt2ZpA2NFSIKvvJbg. Acesso em: 22 mar. 2020.
} 
apresentado. Maiores detalhes deste formulário podem ser obtidos em Avaliação do Curso ${ }^{17}$.

O segundo formulário destina-se à análise do desenvolvimento das alunas durante o curso, na visão dos instrutores. O questionário aplicado aos instrutores continha perguntas que levam em consideração tópicos como: interesse, motivação, atitude, raciocínio e foco das estudantes. As informações coletadas pelo formulário entidade-instrutor, auxiliaram na análise do desempenho das alunas e serviram como dados complementares para o cruzamento de informações para estudar o efeito da tecnologia no caso em estudo. Maiores detalhes deste formulário podem ser obtidos em Avaliação para os Professores ${ }^{18}$.

\subsection{FERRAMENTAS TECNOLÓGICAS PARA ANÁLISE DE DADOS}

Criado em 2014, o Microsoft Power Bl é a ferramenta de Business Intelligence da Microsoft. É um software de análise de dados baseado em nuvem, que pode ser usado para relatórios e análise de uma ampla variedade de fontes. O aplicativo é poderoso e maduro o suficiente para ser usado em sistemas corporativos por desenvolvedores de $\mathrm{BI}$ para cenários complexos e modelagem de dados. Um dos recursos inovadores do Power Bl é o Quick Insight, construído sobre um conjunto de algoritmos analíticos avançados. Uma motivação para o uso deste software é sua usabilidade, na qual permite por meio de simples cliques criar relatórios a partir de uma base de dados.

O Weka é a mais popular ferramenta de mineração de dados gratuito e de código aberto, utilizada em ambiente educacional (SHARDA; DELEN; TURBAN, 2019). Ela foi desenvolvida na Universidade de Waikato, na Nova Zelândia em 1997, e disponibiliza a utilização de diversos algoritmos para mineração de dados, além de possuir uma interface de usuário bem intuitiva. O software, cuja licença é pública, foi desenvolvido em linguagem Java ${ }^{\mathrm{TM}}$.

\section{ANÁLISE DE DADOS SOBRE O EFEITO DA TECNOLOGIA}

\subsection{RELAÇÃO DO DESEMPENHO COM AS DIMENSÕES DO TESTE E GRAU DE SATISFAÇÃO DO CURSO}

A primeira tentativa de obter uma resposta quanto aos efeitos da tecnologia no ensino básico analisado, foi buscando relacionar as variáveis do processo obtidas pela construção do teste descrito na seção 4 , por meio de um modelo matemático baseado em um polinômio de grau 1, conforme a eq. (1),

\footnotetext{
17 Disponível em: https://drive.google.com/open?id=1kSbLrNZdr3wk1vAprajaT5R5EN1SSYqD. Acesso em: 22 mar. 2020.

${ }^{18}$ Disponível em: https://drive.google.com/open?id=1WU79UurxzoMqGAwxmAyWESzQeStXQWV0. Acesso em: 22 mar. 2020.
} 


$$
y=\beta_{0} x_{0}+\beta_{1} x_{1}+\ldots+\beta_{n} x_{n}
$$

onde $\beta_{i}, i=1,2, \ldots, n$, são os parâmetros do modelo, $x$ as variáveis explicativas e $y$ a variável resposta. O fator explícito do erro foi omitido da expressão acima, a fim de simplificar o modelo.

As relações mais simples entre as variáveis são as relações lineares. A partir desta premissa buscou-se um modelo de regressão linear entre as variáveis "Idade" (I), "Acertos" (Ac), "Ângulos" (A), "Lógica" (L), "Resolução" (R), "Pensamento Computacional" (PC), ou seja, um modelo com 6 parâmetros e 6 variáveis. Utilizamos o software Weka para fazer a aplicação do método e inferência dos dados. A base de dados utilizada continha 6 atributos, os quais correspondiam às variáveis do modelo, e 65 instâncias que correspondem as respectivas informações deste quantitativo de alunas respondentes ao teste aplicado. Para a geração do polinômio resultante, utilizamos como base de treinamento a validação cruzada de tamanho 7, o que corresponde a aproximadamente $10 \%$ do tamanho da amostra. A fim de explorar as possibilidades de relacionamento entre as variáveis, obtemos os seguintes polinômios:

Tabela 1: Modelos de Regressão Linear

\begin{tabular}{|c|c|c|}
\hline Modelo & $\begin{array}{c}\boldsymbol{r}^{2} \text { (Coef. de } \\
\text { Determinação) }\end{array}$ & $\begin{array}{c}\rho \text { (Coef. de } \\
\text { Correlação) }\end{array}$ \\
\hline $\mathrm{I}=0,32^{*} \mathrm{R}+13,51$ & 0,0874 & 0,1472 \\
\hline $\mathrm{Ac}=1^{*} \mathrm{~A}+1^{*} \mathrm{~L}+1^{*} \mathrm{R}+1^{*} \mathrm{PC}$ & 1 & 1 \\
\hline $\mathrm{A}=0,31^{*} \mathrm{~L}+2,45$ & 0,1051 & 0,1595 \\
\hline $\mathrm{L}=0,28^{*} \mathrm{~A}+0,24^{\star} \mathrm{R}+0,76$ & 0,1489 & 0,2123 \\
\hline $\mathrm{R}=0,24^{*}+0,19^{*} \mathrm{~L}+0,28^{*} \mathrm{PC}-$ & 0,239 & 0,3648 \\
\hline 1,39 & & 0,2608 \\
\hline $\mathrm{PC}=0,35^{\star} \mathrm{R}+1,10$ & 0,1147 & \\
\hline
\end{tabular}

Fonte: Elaborada pelos autores.

A Tabela 1 exibe os modelos de regressão linear que tentam explicar a relação entre algumas das variáveis explicativas e de resposta do teste, e os coeficientes de determinação $\left(r^{2}\right)$ e de correlação $(\rho)$ que dizem respeito ao ajuste e qualidade do modelo. $\mathrm{O} \boldsymbol{r}^{2}$ pode ser entendido como a proporção da variação total dos dados em torno da média da resposta que é explicada pelo modelo de regressão. Este valor varia entre 0 e 1 , e quanto mais próximo de 1 , mais explicativo é o modelo em relação a amostra analisada. O coeficiente de correlação mede o grau de correlação entre as variáveis, e varia de -1 a 1 . O coeficiente mais próximo de -1 ou 1 , representa uma correlação negativa e positiva, respectivamente, entre as variáveis. Se o valor do coeficiente se aproximar de 0 , significa uma menor dependência linear entre as variáveis. 
A inexistência de alguma variável no modelo gerado pelo software, indica uma pequena significância desta característica na variável resposta. A segunda linha da Tabela 1 mostra que usando todos os dados sobre as dimensões do teste, a quantidade de acertos e a idade das alunas, a variável representativa do desempenho no teste está relacionada com todas as dimensões e com as idades das estudantes. A primeira linha nos diz que a dimensão "Resolução" está relacionada com o fator "Idade". Uma explicação possível seria que o amadurecimento adquirido pela idade poderia estar relacionado com a capacidade de resolução de problemas. A terceira linha nos faz refletir que a base matemática a respeito de ângulos compreendida no teste, pode ter relação com questões lógicas, tornando mais intrínseca a relação entre as duas dimensões. Analisando a quarta linha da Tabela 1, percebe-se que as questões de lógica podem ter sido elaboradas de tal forma que, para solucioná-las seja necessário o conhecimento prévio a respeito de ângulos e também habilidades para resolver problemas. A quinta linha indica que as questões de resolução de problemas se relacionam com a idade da aluna respondente, com o conteúdo de lógica abordado e com a forma de se pensar computacionalmente. Por fim, a dimensão de "Pensamento Computacional", pode estar relacionado com a capacidade de resolução de problemas.

Apesar de toda esta análise, os modelos gerados não conseguem predizer significativamente a relação entre as variáveis, pois tem-se valores muito baixos dos coeficientes de determinação e de correlação. Ainda buscando explorar a relação linear, fizemos uma varredura sobre todas as possibilidades de combinações de variáveis na quantidade de,

$$
\sum_{i=0}^{6}\left(C_{6, i}\right)-C_{6,0}-C_{6,1}=2^{6}-1-6=57 .
$$

O resultado mais significativo estatisticamente foi dado pelo modelo $A c=$ $0,24 * I+1,09 * A+1,12 * L+1,26 * P C-1,59$, o qual indica que $90 \%\left(\boldsymbol{r}^{2}=\mathbf{0}, \mathbf{9 0}\right)$ das variáveis dependentes conseguem explicar os regressores do modelo. Podemos verificar pelos fatores do polinômio do modelo gerado, que as dimensões "Lógica" e "Pensamento Computacional", são as que mais tem representatividade nos resultados do teste aplicado e o fator "Idade" não teve tanto impacto. Isso nos leva a acreditar que independentemente da idade, as alunas podem ter sucesso no teste. Este modelo fornece um coeficiente de correlação muito forte $(\rho=\mathbf{0 , 9 4})$ entre as variáveis.

Outro ponto de reflexão deste estudo incidiu sobre a investigação da relação do desempenho no teste aplicado com o grau de satisfação das alunas. O formulário de avaliação no qual as estudantes responderam sobre a qualidade e percepção do curso continha 25 questões. A fim de construir um indicador que representasse o nível de satisfação das discentes quanto ao curso, elaboramos a seguinte equação a ser calculada para cada estudante:

$$
\text { sat }=1 / d_{c}+1,5 * q_{a t}+2 * q_{a p}+0,2 * q_{b}+1,5 * q_{m d},
$$


sendo sat o indicador de satisfação da aluna, $d_{c}$ o nível de dificuldade do curso atribuído pela aluna, $q_{a t}$ a qualidade das aulas teóricas atribuída pela aluna, $q_{a p}$ a qualidade das aulas práticas e/ou exercícios atribuída pela aluna, $q_{b}$ a qualidade da bibliografia apresentada para estudo atribuída pela aluna e $q_{m d}$ a qualidade do material didático utilizado atribuída pela aluna. As variáveis $d_{c}, q_{a t}, q_{a p}, q_{b}$ e $q_{m d}$ variam de 0 a 5 , sendo 0 classificação mais baixa e 5 a melhor classificação.

Assumimos que o grau de dificuldade do curso pode estar relacionado inversamente com o grau de satisfação do curso. Como o curso era composto por aulas teóricas e práticas, acreditamos que o peso dado à nota das aulas práticas devia ser melhor valorado do que a nota das aulas teóricas, tendo em vista a natureza prática do curso e por este motivo optamos pelos parâmetros 1,5 e 2 para os pesos da qualidade das aulas teóricas e práticas, respectivamente. Apesar de acreditar que uma boa base bibliográfica pode aprimorar a qualidade de um curso, as estudantes de faixa etária presentes no curso, não costumam considerar ou não compreendem com clareza este quesito, por este motivo optamos por um fator de 0,2 , ou seja, de pouco impacto no resultado de satisfação. Acreditamos que o nível do material didático está diretamente relacionado com as aulas teóricas e por este motivo estabelecemos o valor de 1,5 para o parâmetro desta variável.

Utilizando a análise de variância (ANOVA), e considerando o teste de hipótese, cuja hipótese nula $H_{0}: \beta_{1}=0$ corresponde a não existência de correlação linear significativa entre as amostras, e por conseguinte, a hipótese alternativa: $H_{1}: \beta_{1} \neq 0$ indicando a existência de correlação linear entre as amostras, obtivemos 0 seguinte gráfico da Fig. 1 e o com coeficiente de determinação igual a $r^{2}=0,0062$.

Figura 1: Correlação (satisfação, desempenho) pela ANOVA

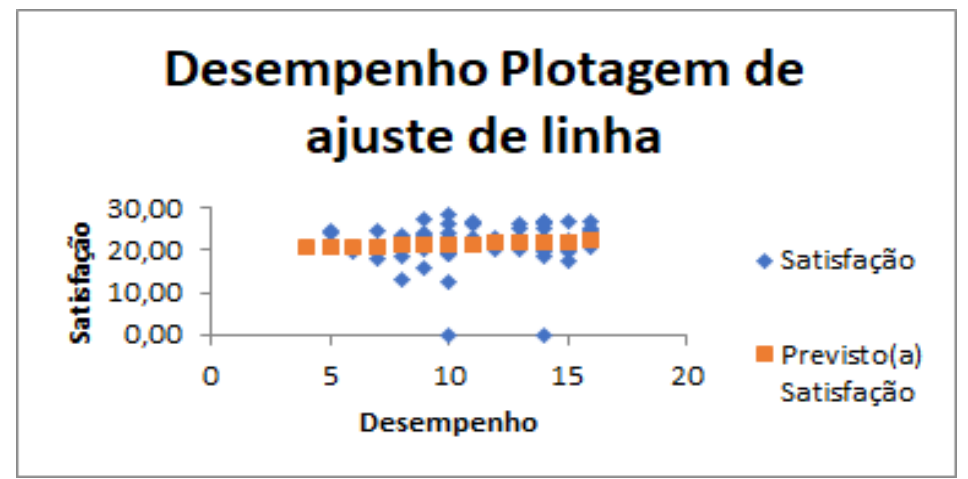

Fonte: Elaborada pelos autores.

Note que o valor de $r^{2}=0,0062$ é muito pequeno, indicando que o ajuste linear não é o mais adequado. Considere a Fig. 2, obtida da aplicação da ANOVA. 
Figura 2: Análise residual e estatística F entre "Satisfação" e "Desempenho"

\begin{tabular}{|l|r|c|c|c|r|}
\hline ANOVA & & & & & \\
\hline & \multicolumn{1}{|c|}{$g l$} & \multicolumn{1}{c|}{$S Q$} & $M Q$ & $F$ & Fde significação \\
\hline Regressão & 1 & 10,10623 & 10,10623 & 0,395546 & 0,531672321 \\
\hline Resíduo & 63 & 1609,655 & 25,55008 & & \\
\hline Total & 64 & 1619,761 & & & \\
\hline
\end{tabular}

Fonte: Elaborada pelos autores.

Ao adotar um nível de confiança de $95 \%$ para análise dos dados referentes ao modelo de satisfação elaborado, a hipótese nula é aceita, pois, de acordo com a Fig. 2 o valor de referência $F$, igual à 0,395536 é bem menor que o valor 4,0012 apresentado na tabela de distribuição de Fischer $^{19}$ para o caso analisado, indicando que o desempenho das alunas tem correlação com o grau de satisfação das mesmas no curso.

\subsection{ANÁLISE DOS DADOS PARA VERIFICAÇÃO DO EFEITO DA TECNOLOGIA}

As Figuras 3 e 4 indicam o quantitativo de acertos e erros das alunas do ensino fundamental e médio, respectivamente, referentes ao teste-base de conhecimento, o qual compreendia as quatro dimensões apresentadas na seção 4 .

Figura 3: Quantitativo de acertos e erros no teste-base de conhecimento realizado pelo nível fundamental

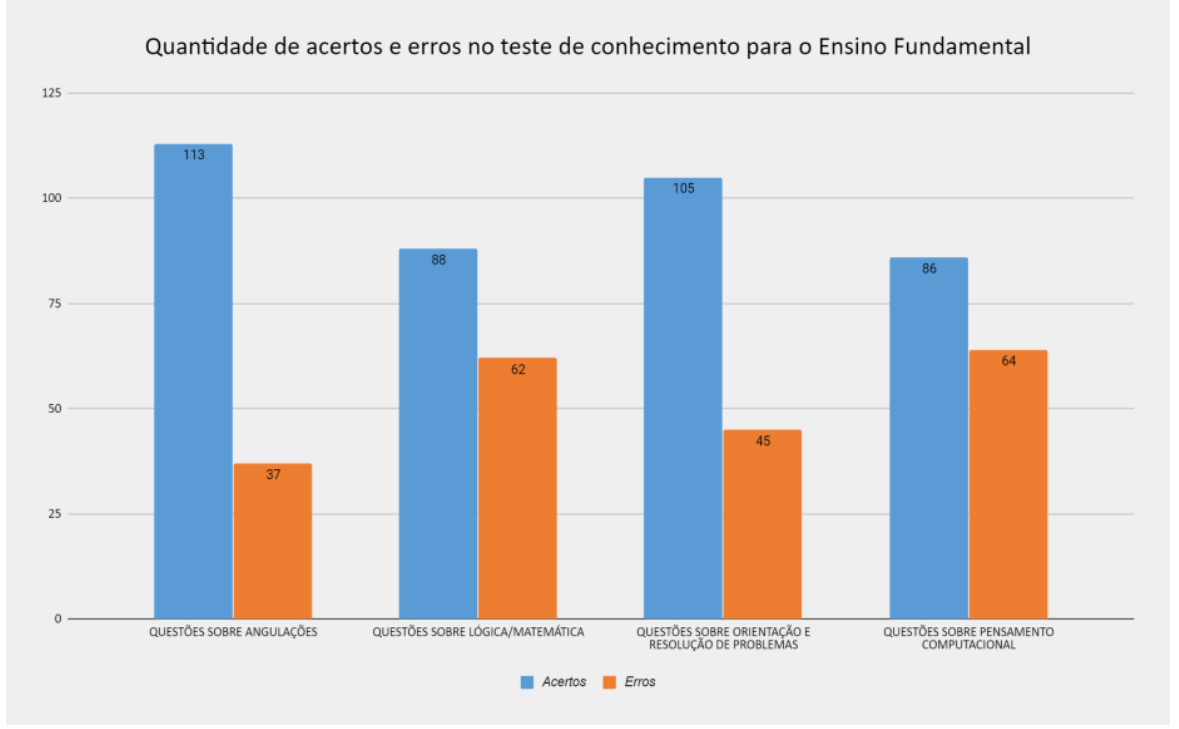

Fonte: Elaborada pelos autores.

\footnotetext{
${ }^{19}$ Disponível em: http://www.socr.ucla.edu/Applets.dir/F Table.html. Acesso em: 30 mar. 2020.
} 
Figura 4: Quantitativo de acertos e erros no teste-base de conhecimento realizado pelo nível médio

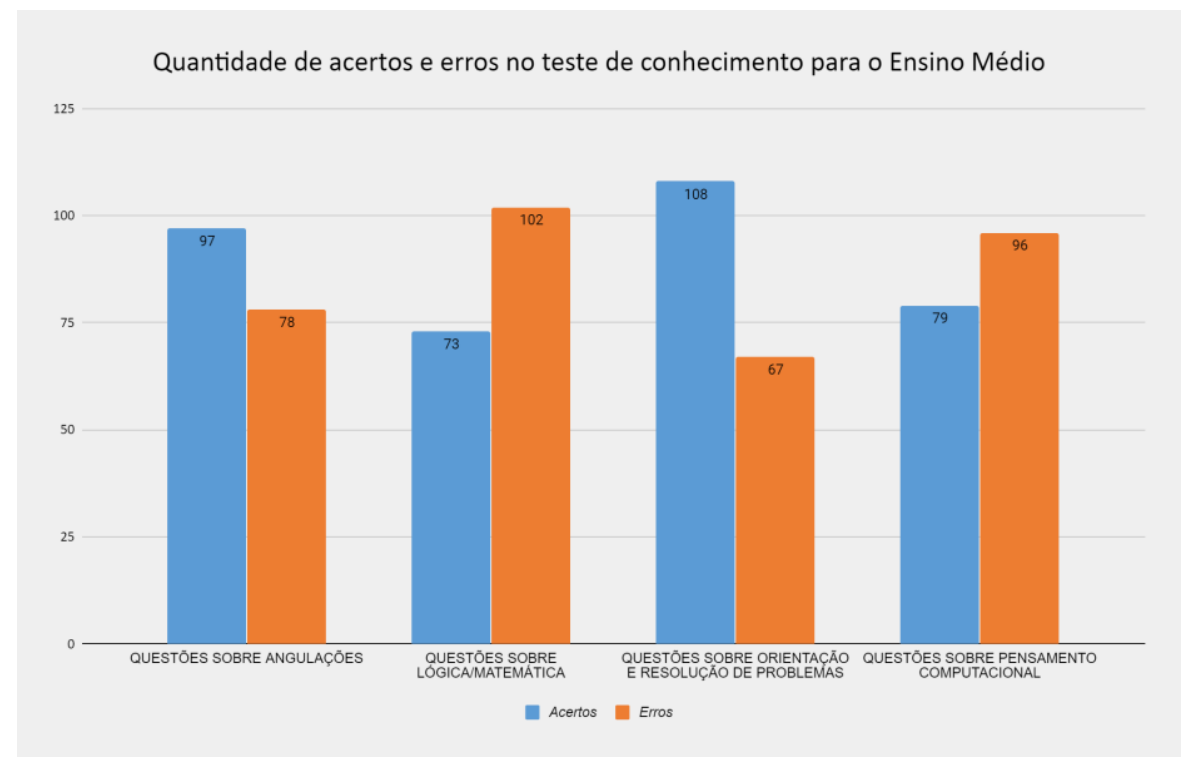

Fonte: Elaborada pelos autores.

Ao invés de avaliar o desempenho dos níveis de ensino considerando a quantidade de acertos e erros, ou a diferença global entre estes, fizemos a análise relativa. Para isso considere a expressão (3):

$$
\operatorname{des}_{A, E}=\left\{\begin{array}{cc}
\frac{(A-E)}{E} & , E \neq 0 \\
A & , E=0
\end{array}\right.
$$

Nesta expressão, des $_{A, E}$ define nosso índice de desempenho em relação a quantidade de acertos $(A)$ e erros $(E)$, sendo normalizado pela quantidade de erros. Note que, se o índice for negativo significa que houve mais erros do que acertos. A Fig. 5 representa o desempenho de acordo com a expressão (3), ao longo das dimensões "Ângulos", "Lógica", "Resolução" e "Pensamento Computacional". 
Figura 5: Desempenho dos níveis de ensino quanto às dimensões do teste-base de conhecimento

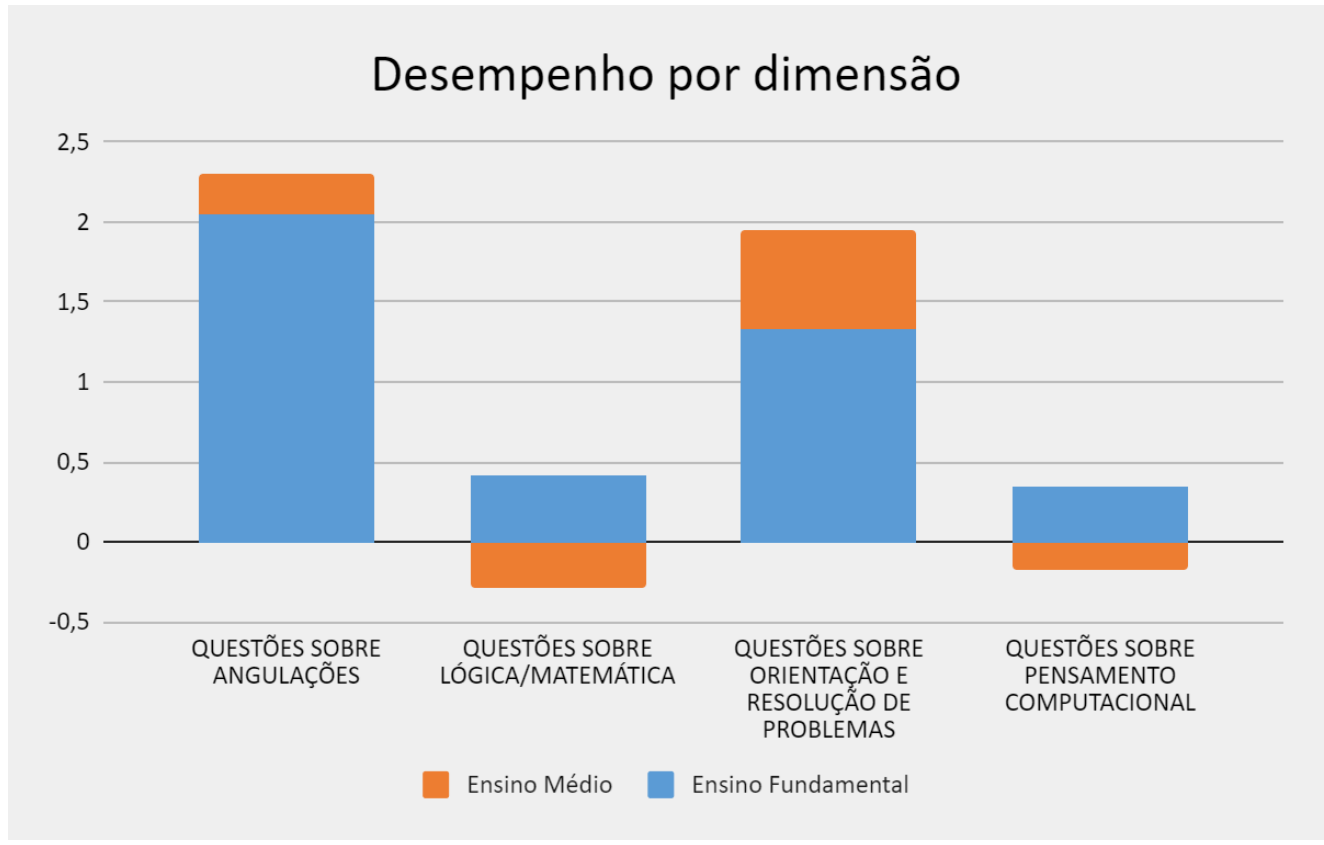

Fonte: Elaborada pelos autores.

A suposição inicial seria que as alunas do ensino médio teriam vantagem nas quatro dimensões do teste, em virtude do amadurecimento proporcionado por suas idades, ou então, em pelo menos na dimensão "Ângulos", a qual está diretamente relacionada a um tópico da matriz curricular do ensino básico. Percebe-se que a suposição não foi corroborada, indicando um melhor aproveitamento do ensino fundamental na dimensão "Ângulos". As dimensões "Lógica" e "Pensamento Computacional" registraram os valores mais baixos de desempenho entre as dimensões, sobretudo para o ensino médio que registrou valores negativos, o que significa que houve mais erros do que acertos. Partindo do mesmo pressuposto da condição de amadurecimento proporcionado pela idade, os resultados do desempenho na dimensão "Resolução", contrariam novamente a suposição, tendo o ensino fundamental obtido o dobro de aproveitamento quando comparado ao ensino médio. Os resultados podem indicar que o ensino de tecnologia já comece a ter efeito positivo no ensino fundamental. A quantidade de discentes pertencentes ao ensino fundamental e ensino médio no projeto, impactam na análise dos resultados. A Fig. 6 mostra o quantitativo de alunas por idade. 
Figura 6: Quantidade de alunas por idade

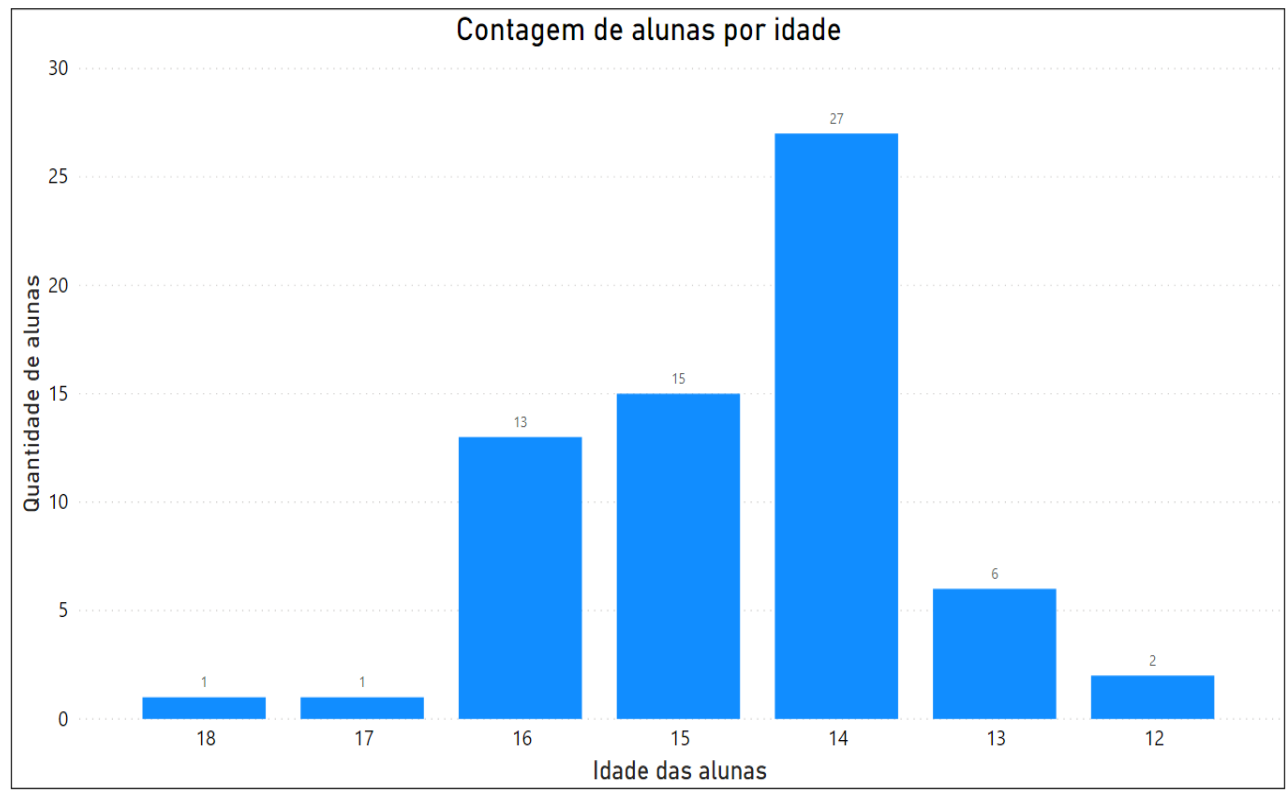

Fonte: Elaborada pelos autores.

Considerando as faixas etárias comuns para o ensino fundamental e ensino médio, tem-se uma divisão balanceada do quantitativo de alunas entre as duas modalidades, porém, percebe-se pela Fig. 7 que há uma predominância das escolas estaduais presentes nas avaliações e sabe-se que de acordo com as diretrizes e bases da educação nacional, o ensino fundamental é competência do município. Porém, essa competência é posta apenas como prioritária, ocorrendo casos em que escolas estaduais também oferecem parte do ensino fundamental, como o estudo de caso analisado. 
Figura 7: Distribuição de alunas por escolas

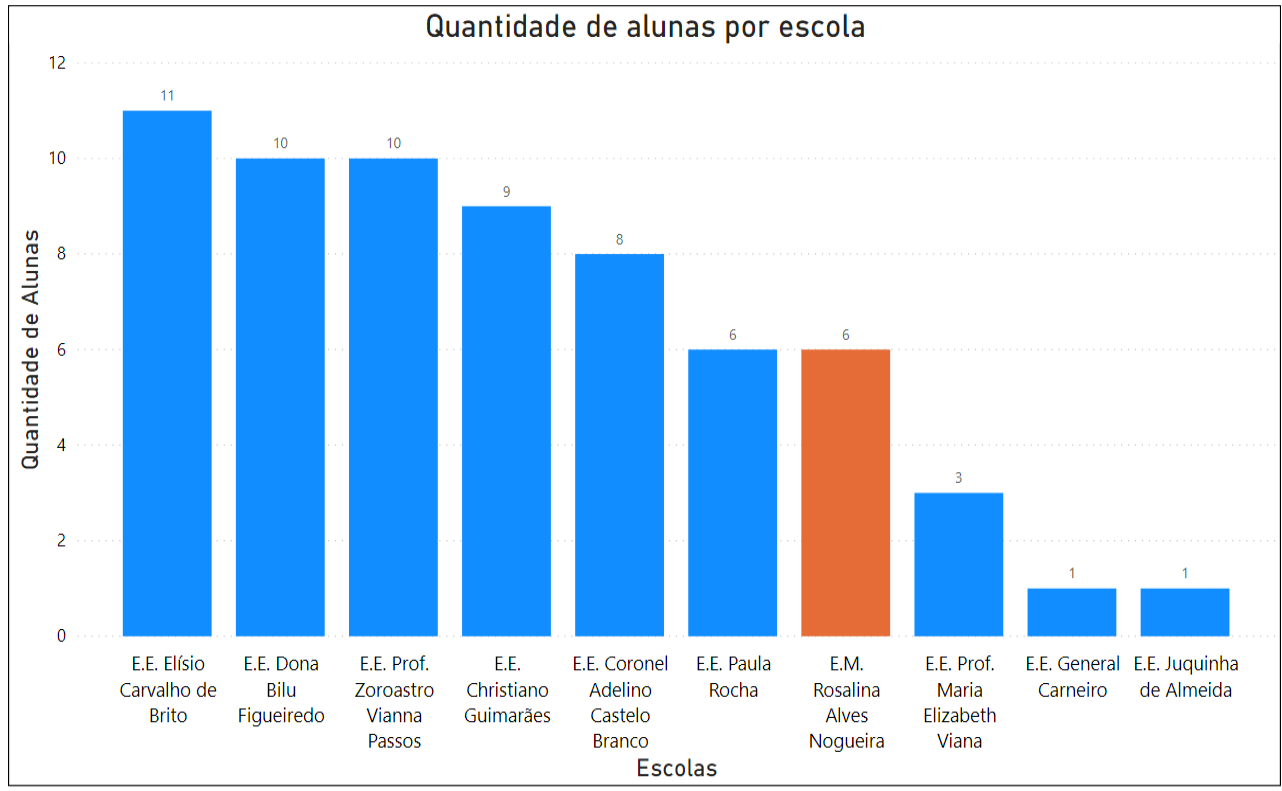

Fonte: Elaborada pelos autores.

Apesar da representação municipal no caso de estudo ser ínfimo, vale ressaltar seu desempenho. Infelizmente, por se tratar de uma única escola no espaço amostral, o efeito de seu resultado no teste pode ter pouca relevância. Porém, ainda sim é interessante enfatizar os resultados obtidos na Tabela 2.

Tabela 2: Performance das escolas no teste-base de conhecimento

\begin{tabular}{|c|c|c|c|c|c|c|}
\hline $\begin{array}{l}\text { Dependên } \\
\text { cias }\end{array}$ & Escola & $\begin{array}{l}\text { Acert } \\
\text { os } \\
(\%)\end{array}$ & $\begin{array}{l}\text { Ângu } \\
\text { los } \\
(\%)\end{array}$ & $\begin{array}{l}\text { Lógi } \\
\text { ca } \\
(\%)\end{array}$ & $\begin{array}{c}\text { Resoluçã } \\
\text { o (\%) }\end{array}$ & $\begin{array}{c}\text { Pensamento } \\
\text { Computacion } \\
\text { al (\%) }\end{array}$ \\
\hline \multirow{4}{*}{$\begin{array}{l}\text { Fora do } \\
\text { IFMG- } \\
\text { Sabará }\end{array}$} & $\begin{array}{l}\text { E.E. Christiano } \\
\text { Guimarães }\end{array}$ & 54,4 & 64,4 & 53,3 & 60 & 40 \\
\hline & $\begin{array}{l}\text { E.E. Dona Bilú } \\
\text { Figueiredo }\end{array}$ & 51,5 & 56 & 50 & 50 & 50 \\
\hline & $\begin{array}{l}\text { E.E. Elísio de } \\
\text { Carvalho Brito }\end{array}$ & 52,7 & 49,1 & 41,8 & 70,9 & 49,1 \\
\hline & $\begin{array}{l}\text { E.E. Prof. } \\
\text { Zoroastro } \\
\text { Vianna Passos }\end{array}$ & 58 & 74 & 48 & 74 & 36 \\
\hline Total & & 54 & 61 & 48 & 64 & 44 \\
\hline $\begin{array}{l}\text { Dentro do } \\
\text { IFMG- }\end{array}$ & $\begin{array}{l}\text { E.E. Coronel } \\
\text { Adelino Castelo } \\
\text { Branco }\end{array}$ & 69,4 & 70 & 62,5 & 85 & 60 \\
\hline
\end{tabular}


Sabará
E.E. General

35

Carneiro

E.E. Juquinha

50 de Almeida

E.E. Paula

Rocha

E.E. Maria

E.M. Rosalina

Alves Nogueira

55

70
Elizabeth Viana

60

20

20

40

60

60

80

0

$44,2 \quad 60$

40

50

26,7

60

26,7

66,7

66,7

93,3

66,7

70

50

Total
67

46

62

Fonte: Elaborada pelos autores.

Analisando o efeito do curso ter sido realizado nas dependências da escola (Fora do IFMG-Sabará) ou nas dependências do instituto (Dentro do IFMG-Sabará), percebe-se que, estatisticamente não há diferença entre os resultados obtidos por dimensão do teste e quantidade de acertos, porém, é notório que dentre as quatro dimensões do teste, além do quantitativo geral de acertos, as alunas que fizeram o curso nas dependências do instituto tiveram o melhor desempenho em todos os critérios. A escola municipal teve a melhor performance em quantitativo de acertos e nas dimensões de "Ângulos", "Lógica" e "Pensamento Computacional" e outra escola estadual, cujas alunas fizeram o curso nos espaços do campus, obtiveram o melhor desempenho na dimensão "Resolução". Além disso, dentre as três primeiras posições de performance em cada dimensão e no quantitativo total de acertos no teste, as escolas em que as alunas fizeram o curso nas dependências do instituto estiveram à frente em 13 posições dentre as 15 possíveis. Uma possível explicação para este fato seria a relevância educacional que o campus representa no município.

\section{CONCLUSÕES}

Este trabalho buscou analisar os efeitos da tecnologia no ensino básico da cidade mineira de Sabará, por meio de um estudo de caso gerado pelo desenvolvimento de um projeto de inclusão digital para o público feminino, o qual envolvia 10 escolas públicas da cidade totalizando 65 meninas com idades variando de 12 a 18 anos. Foram elaborados um teste-base de conhecimento que compreendia dimensões aferidas no curso, além de dois formulários, um para averiguar o nível de satisfação do público-alvo do curso e o outro para indicar o desenvolvimento das alunas no decorrer do projeto. Os três instrumentos foram utilizados para levantar dados, propor hipóteses e analisar a relação de parâmetros que pudesse indicar os efeitos que a tecnologia imputaram no desenvolvimento do projeto de inclusão digital.

Foram propostos modelos matemáticos simples, utilizando regressão polinomial linear, para explicar o impacto e a relação entre si das dimensões do teste- 
base de conhecimento proposto. Os resultados obtidos mostraram que as dimensões de "Lógica" e "Pensamento Computacional" são as que mais tem representatividade nos resultados do teste aplicado. Além disso, outra questão interessante alcançada com os testes foi que o fator "Idade" não teve tanto impacto nos resultados, nos levando à conclusão que independentemente da idade, as alunas podem ter sucesso no teste. Foi criado um indicador de satisfação levando em consideração os formulários elaborados, concluindo que o desempenho das estudantes se correlacionava com o grau de satisfação perante ao curso. Foi possível constatar o impacto e a relação das dimensões do teste de conhecimento à cada escola do estudo de caso. Percebeu-se que as alunas do ensino fundamental tiveram um desempenho tão bom ou superior às alunas do ensino médio, mesmo considerando, supostamente, o maior nível de conhecimento e amadurecimento das discentes do ensino médio. Por fim, constatou-se que o desenvolvimento das atividades nas dependências do IFMGSabará produziu um efeito positivo quanto ao aprendizado das alunas e ao desempenho no teste, cumprindo a missão dos Institutos Federais como parte de uma política educacional que objetiva potencializar a qualidade da educação, bem como o processo de expansão e interiorização de suas unidades.

\section{REFERÊNCIAS}

ALMEIDA, M. E. B. Educação e tecnologias no Brasil e em Portugal em três momentos de sua história. In: Educação, Formação \& Tecnologias; vol.1(1), pp. 23-36, 2008. Disponível em: http://www.eft.educom.pt/index.php/eft/article/view/19/11. Acesso em: 23 fev. 2020.

ARRUDA, E. E.; RASLAN, V. G. S. A implementação do Programa Nacional de Informática na Educação (PROINFO), no Brasil e no estado de Mato Grosso do Sul, no período de 1997 a 2006. In: VII Jornada do HISTEDBR, 2007, Campo Grande. Anais do VII HISTEDBR. Campo Grande: UNIDERP, 2007. Disponível em: http://www.histedbr.fe.unicamp.br/acer histedbr/jornada/ jornada7/03trab-gt-gt2.htm. Acesso em: $11 \mathrm{fev} .2020$.

BERGER, G. The jobs of tomorrow: Linkedln's 2020 emerging jobs report. Linkedln Official blog, 2019. Disponível em:

https://business.linkedin.com/content/dam/me/business/en-us/talent-

solutions/emerging-jobs-report/Emerging_Jobs_Report_U.S._FINAL.pdf. Acesso em: 10 jan. 2020.

BERRY, M. Computing in the national curriculum: A guide Computing in the national curriculum: A guide for primary teachers. Bedford, UK: NAACE - Computing at School, v. 19, 2013. Disponível em:

https://community.computingatschool.org.uk/files/6703/original.pdf. Acesso em: 17 jan. 2020.

\section{BRACKMANN, C. P. Desenvolvimento do pensamento computacional através} de atividades desplugadas na educação básica. 2017. $226 \mathrm{f}$. Tese (Doutorado em Informática na Educação) - Centro de Estudos Interdisciplinares em Novas Tecnologias na Educação, Universidade Federal do Rio Grande do Sul, Porto Alegre, 2017. Disponível em: http://hdl.handle.net/10183/172208. Acesso em: 14 mar. 2020. 
BRASIL. Ministério da Educação. Base nacional comum curricular. Brasília: MEC/SEB, 2018. Disponível em:

http://basenacionalcomum.mec.gov.br/images/BNCC El EF 110518 versao final site.pdf. Acesso em: 10 jan. 2020.

BREINER, J. M; HARKNESS, S. S.; JOHNSON, C. C.; KOEHLER, C. M. What is STEM? A discussion about conceptions of STEM in education and partnerships. School Science and Mathematics, v. 112, n. 1, p. 3-11, 2012. Disponível em: https://doi.org/10.1111//.1949-8594.2011.00109.x. Acesso em: 10 jan. 2020.

CARVALHO, M. L. B.; CHAIMOWICZ, L.; MORO, M. M. Pensamento computacional no ensino médio mineiro. In: Anais do XXI WEI, p. 640-649, 2013. Disponível em: http://www.bitgirls.dcc.ufmg.br/assets/pdf/2013.WEl.deCarvalho.pdf. Acesso em: 23 fev. 2020.

DAGIENÉ, V.; JEVSIKOVA, T.; STUPURIENÉ, G. Introducing Informatics in Primary Education: Curriculum and Teachers' Perspectives. In: International Conference on Informatics in Schools: Situation, Evolution, and Perspectives. Springer. 2019. p. 83-94. Disponível em: https://doi.org/10.1007/978-3-030-33759-9 24. Acesso em: 17 jan. 2020.

DE ARAÚJO, A. P. F.; DE SOUZA, P. R.; DE MIRANDA SILVA, J. A. Uso do scratch no processo de aprendizagem em sala de aula: relato de experiências de alunos do mestrado profissional de ensino tecnológico/IFAM. Revista Brasileira da Educação Profissional e Tecnológica, v. 1, n. 7, p. 125-136, 2014. Disponível em: http://www2.ifrn.edu.br/ojs/index.php/RBEPT/article/view/3473/1416. Acesso em: 25 out. 2020.

FERNANDES, C. T.; SANTOS, N. Pesquisa e desenvolvimento em informática na educação no Brasil-parte 1. Revista Brasileira de Informática na Educação, v. 4, n. 1, p. 9-32, 1999. Disponível em: https://www.br-

ie.org/pub/index.php/rbie/article/download/2290/2052. Acesso em: 11 fev. 2020.

FRANÇA, R.; TEDESCO, P. Desafios e oportunidades ao ensino do pensamento computacional na educação básica no Brasil. Anais dos Workshops do

Congresso Brasileiro de Informática na Educação. Maceió: p. 1464-1473, 2015. Disponível em: http://dx.doi.org/10.5753/cbie.wcbie.2015.1464. Acesso em: 25 fev. 2020.

GAL-EZER, J. Computer science teachers' certification program. Computers \& Education, v. 25, n. 3, p. 163-168, 1995. Disponível em: https://doi.org/10.1016/0360-1315(95)00040-2. Acesso em: 17 jan. 2020.

GARCÍA-PEÑALVO, F. J. A Spanish proposal for teaching Informatics in preuniversity studies. Journal of Information Technology Research, v-viii. 2019. Disponível em: https://www.br-ie.org/pub/index.php/rbie/article/download/2290/2052. Acesso em: 17 jan. 2020.

GAZIRE, E. S. O não resgate das geometrias. 2000. 217p. Tese (doutorado) Universidade Estadual de Campinas, Faculdade de Educação, Campinas, SP. Disponível em: http://www.repositorio.unicamp.br/handle/REPOSIP/252634. Acesso em: 08 mar. 2020.

GROVER, S.; PEA, R. Computational thinking in K-12: A review of the state of the field. Educational researcher, v. 42, n. 1, p. 38-43, 2013. Disponível em: https://doi.org/10.3102/0013189X12463051. Acesso em: 15 mar. 2020. 
HROMKOVIČ, J. Contributing to general education by teaching informatics. International Conference on Informatics in Secondary Schools-Evolution and Perspectives. Berlin, Heidelberg: Springer. 2006. p. 25-37. Disponível em: https://doi.org/10.1007/11915355 3. Acesso em: 28 jan. 2020.

LATHIFAH, A.; BUDIYANTO, C. W.; YUANA, R. A. The contribution of robotics education in primary schools: Teaching and learning. AIP Conference Proceedings. 2019. p. 020053. Disponível em: https://doi.org/10.1063/1.5139785. Acesso em: 28 jan. 2020.

LOCKWOOD, J.; MOONEY, A. Computational Thinking in Education: Where does it fit? A systematic literary review. International Journal of Computer Science Education in Schools. 2. 2017. Disponível em: https://arxiv.org/pdf/1703.07659. Acesso em: 28 jan. 2020.

LORENZATO, S. Por que não ensinar Geometria? In: Educação Matemática em Revista. Blumenau: SBEM, ano III. n. 4, 1995, p. 3-13.

MARQUES, V. D.; CALDEIRA, C. R. C. Dificuldades e carências na aprendizagem da Matemática do Ensino Fundamental e suas implicações no conhecimento da Geometria. Revista Thema, v. 15, n. 2, p. 403-413, 2018. Disponível em: http://dx.doi.org/10.15536/thema.15.2018.403-413.851. Acesso em: 08 mar. 2020.

MELENDEZ, T. T.; EICHLER, M. L. GAMIF-A CULTURA GAME MAKER NA EDUCAÇÃO PROFISSIONAL: UM ESTUDO DE CASO. Revista Brasileira da Educação Profissional e Tecnológica, v. 2, n. 17, p. 8160, 2019. Disponível em: http://www2.ifrn.edu.br/ojs/index.php/RBEPT/article/view/8160/pdf. Acesso em: 25 out. 2020.

MENEZES, E. C. P. Informática e Educação Inclusiva: discutindo limites e possibilidades. 2005. 165 f. Dissertação (Mestrado em Educação) - Universidade Federal de Santa Maria, Santa Maria, 2005. Disponível em: https://repositorio.ufsm.br/handle/1/6792. Acesso em: $11 \mathrm{fev} .2020$.

MOREIRA, E. S.; LIMA, E. O.; BRITO, R. O. Estudo Comparado das Políticas Públicas Educacionais de Inclusão Digital: Brasil e Uruguai. Revista da Faculdade de Educação, Mato Grosso, v. 32, n. 2, p. 17-41, 2020. Disponível em: http://www2.unemat.br/revistafaed/content/AHEAD OF PRINT/2019/Ahead of print ESTUDO COMPARADO DAS POLITICAS PUBLICAS EDUCACIONAIS DE IN CLUSAO DIGITAL BRASIL EURUGUAl.pdf. Acesso em: 23 fev. 2020.

NGUYEN, N. R.; POLIAKOVA, I.; MEDURI, S.; HUTCHENSON, J.; KE, R. CodeNC: Integrating Computational Thinking into K-12 Instructional Activities using Animated Videos. Proceedings of the 50th ACM Technical Symposium on Computer Science Education. Minneapolis, p. 1276-1276, 2019. Disponível em: https://doi.org/10.1145/3287324.3293835. Acesso em: 17 jan. 2020.

PAVANELLO, R. M. O abandono de ensino de geometria: uma visão histórica. 1989. 196f. Dissertação (Mestrado em Educação) - Universidade Estadual de Campinas, Faculdade de Educação, Campinas, São Paulo, 1989. Disponível em: http://www.repositorio.unicamp.br/handle/REPOSIP/252057. Acesso em: 08 mar. 2020.

POSADA, J. E. G.; BUCHDID, S. B.; BARANAUSKAS, M. C. C. A informática na educação: o que revelam os trabalhos publicados no Brasil. Revista Brasileira de 
Informática na Educação, v. 24, n. 1, p. 142, 2016. Disponível em:

http://dx.doi.org/10.5753/rbie.2016.24.1.142. Acesso em: 23 fev. 2020.

SANTOS, A. O.; OLIVEIRA, G. S. A. Prática Pedagógica Em Geometria Nos Primeiros Anos Do Ensino Fundamental: Construindo Significados. Revista Valore, v. 3, n. 1, p. 388-407, 2018. Disponível em:

https://revistavalore.emnuvens.com.br/valore/article/download/85/102. Acesso em: 08 mar. 2020.

SHARDA, R.; DELEN, D.; TURBAN, E. Business Intelligence e Análise de Dados para Gestão do Negócio. 4å. ed. Bookman Editora, 2019.

TRÄFF, U.; OLSSON, L.; SKAGERLUND, K.; SKAGENHOLT, M.; ÖSTERGREN, R. Logical Reasoning, Spatial Processing, and Verbal Working Memory:

Longitudinal Predictors of Physics Achievement at Age 12-13 Years. Frontiers in psychology, v. 10, p. 1-9, 2019. Disponível em:

https://doi.org/10.3389/fpsyg.2019.01929. Acesso em: 14 mar. 2020.

VALENTE, J. A.; ALMEIDA, F. J. Visão analítica da informática na Educação no Brasil: a questão da formação do professor. In: Revista Brasileira de Informática na Educação, n. 1. Florianópolis, p. 45 - 60, 1997. Disponível em: http://www.brie.org/pub/index.php/rbie/article/download/2324/2083. Acesso em: 11 fev. 2020.

VENDRUSCULO, V.; DA SILVA MELLO, C. A. Integração de atividades experimentais e tecnologias educacionais no ensino do conceito de $\mathrm{pH}$. Revista Brasileira da Educação Profissional e Tecnológica, v. 2, n. 19, p. 9065, 2020. Disponível em: http://www2.ifrn.edu.br/ojs/index.php/RBEPT/article/view/9065/pdf. Acesso em: 25 out. 2020.

WING, J. M. Computational thinking. Communications of the ACM, v. 49, n. 3, p. 33-35, 2006. Disponível em : https://doi.org/10.1145/1118178.1118215. Acesso em: 17 jan. 2020. 